\title{
Correction \\ Correction: Devasahayam, S. Decarbonising the Portland and Other Cements-Via Simultaneous Feedstock Recycling and Carbon Conversions Sans External Catalysts. Polymers 2021, 13,2462
}

Sheila Devasahayam (1)

check for updates

Citation: Devasahayam, S

Correction: Devasahayam, S.

Decarbonising the Portland and

Other Cements-Via Simultaneous

Feedstock Recycling and Carbon

Conversions Sans External Catalysts.

Polymers 2021, 13, 2462. Polymers

2022, 14, 281. https://doi.org/

$10.3390 /$ polym 14020281

Received: 30 November 2021

Accepted: 8 December 2021

Published: 11 January 2022

Publisher's Note: MDPI stays neutral with regard to jurisdictional claims in published maps and institutional affiliations.

Copyright: (C) 2022 by the author. Licensee MDPI, Basel, Switzerland. This article is an open access article distributed under the terms and conditions of the Creative Commons Attribution (CC BY) license (https:// creativecommons.org/licenses/by/ $4.0 /)$.
Department of Chemical Engineering, Faculty of Science and Engineering, Monash University, Melbourne 3800, Australia; sheiladevasahayam@gmail.com

The author wishes to make the following correction to the above paper: [1]. In the original version of the published article, there is a mistake in Equation (16) on Page 14. It should be:

$$
\mathrm{CH}_{4}+2 \mathrm{H}_{2} \mathrm{O} \rightarrow \mathrm{CO}_{2}+4 \mathrm{H}_{2}(\Delta \mathrm{H} 298 \mathrm{~K}=+165 \mathrm{~kJ} / \mathrm{mol})
$$

The author apologises for any inconvenience caused to the readers by these changes. These changes have no material impact on the conclusions of our paper. The original article has been updated.

\section{Reference}

1. Devasahayam, S. Decarbonising the Portland and other Cements-Via Simultaneous Feedstock Recycling and Carbon Conversions Sans External Catalysts. Polymers 2021, 13, 2462. [CrossRef] [PubMed] 